\title{
La OLAS y la crisis política en América latina
}

\begin{abstract}
C L O DOM I R O A M E Y A es Director de la Escuela de Sociologia de la Universidad de Chile. Fue Ministro de Minerfa y del Trabajo durante la segunda administración del Presidente Carlos Ibáñez y sirviós como Diputado entre 1961 y 1965. Sus principales publicaciones incluyen, Hacia una teoria marxista del estado, 1948; Reflexiones políticas, 1955; Vision sociológica de Chile, 1957. .
\end{abstract}

La creación de la Organización Latinoamericana de Solidaridad (oLAs) con oportunidad de la realización en La Habana de la Conferencia Tricontinental en enero de 1966, y su constitución formal en la Primera Conferencia de Solidaridad de los Pueblos de América latina en agosto de 1967, también en La Habana, representan el comienzo de una nueva etapa dentro del proceso de la izquierda revolucionaria de América latina en procura de una línea y de una conducta políticit adecuadas a las nuevas circunstancias imperantes en el mundo y en el continente desde hace una decena de años.

\section{LiA DOĠTrINA DE OLAS}

El objeto del presente artículo es analizar lo que pudiéramos llamar la "doctrina de la oLAs", entendida como el conjunto coherente de ideas que informan su fundamentación ideológica, su estructura orgánica y su programa de acción, tal como resultan y se desprenden del estudio de los documentos emanados de las conferencias de $\mathrm{La}$ Habana ya mencionadas, de las ponencias e infonmes públicos que alli se discutieron y de los puntos de vista escritos de sus voceros ideológicos informales más representativos ${ }^{1}$.

Los puntos de vista teóricos que informan la doctrina de la oLAs y que explican el nacimiento de la entidad importan una toma de conciencia por parte de las fuerzas de izquierda mayoritariamente representadas en los torneos de La Habana, de las nuevas condiciones

${ }^{1}$ Como antecedentes y fuentes complementarias hay que considerar la Segunda Declaracion de La Habana y la Declaración General de la Conferencia Tricontinental, en cuyo mareo se realiz 6 la Conferencia de olas. 
prevalecientes en América latina en el último decenio, condiciones que definen una nueva situación política, frente a la cual la izquierda revolucionaria del continente debió asumir una nueva línea y una nueva conducta correspondiente a la naturaleza de la nueva situación.

\section{LA NUUEVA SITUACIÓN POLÍTICA LATINOAMERICANA}

¿Cuáles son los hechos y rasgos que configuran esta nueva situación político-social en el continente y que se han ido evidenciando en el transcurso de los últimos años?

En primer lugar, la Revolución Cubana, su progresiva radicalización y su inserción en el movinuiento comunista internacional y en el sistema de estados socialistas. De resultas de estos hechos, el antagonismo entre los Estados Unidos y Cuba, el bloqueo continental de la isla promovido por aquel país, la expulsión de Cuba de la Organización de Estados Americanos y su aislamiento diplomático hemisférico.

En segundo lugar, y directamente vinculada a los hechos expuestos, la asunción por Cuba revolucionaria de un liderazgo informal de gran parte del movimiento popular latinoamericano, la progresiva radicalización del mismo y la emergencia bajo ese influjo de movimientos subversivos guerrilleros en varias partes del continente de muy desigual trascendencia y desenlace.

En tercer lugar, la formulación por los Estados Unidos, como respuesta al desafío planteado por la Revolución Cubana, de la política llamada de la Alianza para el Progreso, destinada a promover cambios institucionales que alivien la tensión social en el continente, bajo el liderazgo de fuerzas sociales y políticas moderadas y dentro de los marcos de la estructura capitalista imperante.

En cuarto lugar, la pronta frustración de las esperanzas cifradas en la Alianza para el Progreso y el fracaso y derrumbe de muchos de los gobiernos desarrollistas inspirados en ella y su sustitución por regímenes autoritarios, militaristas y reaccionarios, con el beneplácito de los Estados Unidos.

En quinto lugar, los intentos de fortalecer y transformar a la OEA en una estructura política supranacional, destinada a defender las "fronteras ideológicas" del orden social imperante y a asumir la dirección estratégico-militar de la contrarrevolución. Vale la pena consignar al respecto los intentos de crear la llamada Fuerza Interamericana de Paz, las tentativas actuales por concertar pactos militares subregionales antiguerrilleros, el adiestramiento bajo mando americano de destacamentos antiguerrilleros en todos los ejércitos del continente y 
la red de acuerdos militares que ligan a las fuerzas armadas de Amé. rica latina con Ia política y los intereses del Pentagóno, como asimismo la intervención activa de las fuerzas antiguerrilleras norteamericanas en la lucha represiva en Colombia, Perú, Bolivia, etc.

En sexto lugar, la invasión armada de Santo Domingo, para precaver la radicalización del proceso político en ese país y la formulación a su respecto de la llamada Doctrina Johnson, en cuya virtud los Estados Unidos afirman su voluntad de intervenir armada y unilateralmente, si es necesario, para impedir que un país latinoamericano se convierta en una segunda Cuba.

$\mathrm{Y}$ en séptimo:lugar, el fracaso de la izquierda tradicional en contener esta marea reaccionaria y su incapacidad para conquistar el poder por vías legales y electorales, sea por la obstrucción de los canales institucionales cuando su victoria es inminente, sea por el desconocimiento de sus triunfos electorales cuando los ha obtenido, sea por su debilidad para hacer frente a la "Santa Alianza" de todas las fuerzas más o menos conservadoras, bajo liderazgo norteamericano, que la relegan electoralmente a una condición minoritaria, como en el caso de Ghile.

\section{LA RESPUESTA A ra NUEVA SITUACIóN}

El cuadro político continental configurado por los hechos y rasgos así definidos, lleva a una doble conclusión: primero, la caducidad y obsolescencia de las vías legales, electorales y pacíficas de acceso al poder por la izquierda revolucionaria, en la medida que en último término la fuerza armada de los Estados Unidos ha asumido en la teoría (Doctrina Johnson) y en la práctica (Santo Domingo) el papel de gendarme armado del orden establecido. En segundo lugar, la imposibilidad de que un país latinoamericano, aisladamente, pueda repetir la experiencia cubana, ya que el intento de hacerlo lo enfrentaría a una reacción internacionalizada en su contra. No habrá ya, pues, una segunda Cuba.

Esto significa que las fuerzas conservadoras del continente han elaborado y comenzado a poner en práctica una estrategia común, bajo liderazgo norteamericano, que reviste un doble carácter: es armada y es continental.

La respuesta a esta estrategia armada y continental de la contrarrevolución tiene que ser, pues, necesariamente, la adopción por el movimiento revolucionario de América latina de una estrategia de lucha. también armada y también continental. 
Para la debida inteligencia del alcance y perspectivas de la lucha revolucionaria de los pueblos latinoamericanos, armada y continental, es preciso enfocarla dentro de un contexto político general, cuyas características más relevantes es necesario explicar.

La primera de esas características del contexto politico general, es la caducidad dél capitalismo mundial como sistema. Vale decir, el capitalismo en su conjunto y en escala mundial, ha perdido su carácter progresivio y ha creado también, globalmente, las circunstancias necesarias para su reemplazo por la sociedad socialista. Esta característica básica del momento que vive el mundo quiere decir que las fuerzas productivas generadas por el capitalismo y su tecnología, que es su producto, son capaces de resolver objetivamente las necesidades del mundo en su conjunto, incluso la de los pueblos subdesarrollados. $\mathrm{Y}$ si esas posibilidades objetivas de la tecnología no se actualizan, es por la subsistencia en escala mundial del orden capitalista, cuya irracionalidad esencial impide que se utilice en beneficio del hombre el poderio económico y técnico que está virtualmente a su disposición.

La primera de esas características del contexto político general, es del capitalismo se desarrollen tendencias secundarias en sentido contrario, que todavía expresan virtualidades progresivas suyas, como el crecimiento económico de Europa occidental en la postguerra, no invalida la tesis básica de que el mundo capitalista, como totalidad y en su conjunto, está maduro para la emergencia del socialismo. Se confirma así la tesis ya clásica, que define la hora actual, desde la Revolución de Octubre en adelante, como la era de la transformación revolucionaria del capitalismo al socialismo.

Ahora bien, esta obsolescencia del capitalismo como sistema, mundialmente considerado, se manifiesta especialmente en su incapacidad para resolver la problemática social y económica de los países dependientes de Asia, Africa y América latina. En esta área del mundo, que es la más extensa y poblada, se hace evidente el fracaso del sistema capitalista para promover el desarrollo económico, satisfacer las apremiantes necesidades de las masas sumidas en la miseria y mantener la estabilidad social y politica deseables.

En otras palabras, para los pueblos paupérrimos del Tercer Mundo, es evidente que el actual orden no los satisface y surge de allí un descontento general, fuente a su vez de aguda tensión social y politica.

Esto es particularmente válido para América latina, donde por razones especiales, es mayor el grado de frustración y desesperación de los pueblos. 
El agudo descontento de las masas latinoamericanas y la incapacidad del sistema para remediarlo es el hecho básico que determina que en nuestro continente existan las condiciones objetivas para que se desarrolie un proceso revolucionario triunfante.

La existencia de condiciones objetivas para iniciar, desarrollar y hacer triunfar un proceso revolucionario, no quiere decir que en América latina exista una situación revolucionaria, en el sentido que la. definió Lenin. No, globalmente considerado el continente, no existe aque una situación revolucionaria que haga inminente y viable un derrumbe del orden actual y su substitución por un orden revolucionario. Pero sí existen las condiciones para que subjetivamente se recojan esas circunstancias favorables para el desarrollo del proceso revolucionario y se conviertan en un movimiento político cuya tarea sea precisamente transformar las condiciones revolucionarias en una situación revolucionaria.

La segunda de esas características del contexto sociopolítico general en que se inserta el movimiento revolucionario latinoamericano, es la pérdida de toda virtualidad progresiva y potencialidad renovadora de las burguesías nacionales del continente. $Y$ ello por dos razones. En primer lugar, por su cada vez más estrecha alianza con el imperialismo yanqui y con las fuerzas sociales representativas del orden tradicional, que las ha convertido en una fuerza social politicamente pro imperialista y conservadora. Y en segundo lugar, porque al colocarse el proceso polftico en el continente después de la Revolución Cubana en un plano en que lo que se cuestiona son las bases propietarias del orden social, la burguesía define su comportamiento político esencial en función del antagonismo entre la Revolución y la contrarrevolución, y no entre la modernidad y el tradicionalismo, como hasta hace poco tiempo se presumfa y sostenfa.

Consecuencialmente, no es la alianza entre el proletariado, el campesinado y la burguesía nacional progresista, la base social de la auténtica izquierda latinoamericana, sino lo es virtualmente la alianza entre la clase obrera, el campesinado, la pequeña burgueśa pauperizada y la intelectualidad revolucionaria.

Ahora bien, es tarea del movimiento revolucionario producir bajo su liderazgo y en el curso de la lucha contra el sistema, esa alianza de clases y sectores sociales que está latente en nuestra realidad social y que es necesario actualizar y promover.

\section{LA LUGHA ARMADA Y CONTINENTAL}

Precisados estos contornos del contexto sociopolítico de la lucha emancipadora de los pueblos latinoamericanos en la nueva situación 
del continente, procede examinar con mayor detención los dos rasgos que deben caracterizar al movimiento revolucionario en la actualidad, su carácter armado y su carácter continental.

En lo concerniente al carácter armado que debe revestir la lucha revolucionaria en América latina, es menester destacar que ello no deriva en sf, de las nuevas condiciones de la situación sociopolítica del continente. El carácter en último término violento que está asumiendo en América latina el proceso político, deriva de la naturaleza esencial de toda lucha política que se eleva al nivel de la pugna por el poder estatal. Es de la esencia del Estado ser violencia organizada y sistematizada al servicio de intereses de clase, de manera que siempre, en todo tiempo y lugar, el problema del desplazamiento de una clase por otra del poder se resuelve en último término en el plano de la violencia y de la fuerza armada. Lo que sí ha aportado a esta cuestión de la lucha armada la nueva situación continental que describimos al comenzar este artículo, es la puesta en evidencia ante las masas del carácter armado de la lucha polftica, que hasta hace poco aparecía encubierto y disfrazado ante sus ojos por una engañosa $y$ falaz teoría que ilusionaba a los pueblos sobre las posibilidades de llegar al poder por vías pacificas. La conducta del imperialismo y sus agentes nativos en América latina durante los últimos años, ha hecho caer los velos que disimulaban el carácter coercitivo y violento de su dominación de clase. Antes de que se configurara el nuevo cuadro poĺ́tico como resultado de la Revolución Cubana, tal circunstancia aparecía oculta para las masas, después, la verdadera naturaleza violenta del proceso político en su culminación, aparece desnuda y descarnada ante ellas, entonces es ya posible que conscientemente se apresten y organicen para oponer la violencia revolucionaria a la violencia contrarrevolucionaria.

Así planteadas las cosas, no cabe oponer como formas alternativas de acción polftica, la lucha armada y la lucha de masas. Toda lucha politica tiende a culminar y a expresarse superlativamente como lucha armada, y a su vez toda lucha política victoriosa requiere para vencer haberse convertido en una lucha de masas, en el sentido que toda revolución triunfante requiere para su victoria el apoyo y la fuerza que le dan las masas que la respaldan.

Lo que si cabe distinguir es entre formas armadas y no armadas de lucha, incluyendo entre éstas a la lucha económica, las luchas electorales, la lucha ideológica, etc. Si la lucha armada es la forma superior de la lucha política en la medida que es en último término la violencia la que decide o da el golpe final al poder estatal de clase, esto quiere decir que todas las demás formas de lucha deben subor- 
dinarse a la lucha armada, en el sentido que deben contribuir a desencadenarla, a fortalecerla y a hacerla triunfar. Las formas no violentas de lucha tienen asi un papel importantisimo que jugar, determinante incluso muchas veces, pero siempre que se inserten en un proceso que estratégicamente tenga en vista la necesidad de su desenlace violento.

Si por el contrario, las formas no violentas de lucha, sea esta electoral o reivindicacionista o de cualquier otro género, se desarrollan desconociendo u olvidando el necesario carácter armado de la culminación del proceso político, ello no conduce a la victoria revolucionaria sino a su debilitamiento, mediante la inserción más o menos paulatina y progresiva del movimiento popular en los mecanismos integrativos del sistema, que pasan a ser un expediente más, destinado a amortiguar y desorientar el sentido y el alcance revolucionario de su impulso inicial.

Las formas de luoha no armada son concebidas, pues, como formas temporales y limitadas de la lucha política. Temporales, porque más tarde o más temprano el conflicto político se ha de elevar al plano armado si de la lucha por el poder se trata. Limitadas, porque aunque eștas formas de lucha pueden debilitar al adversario y robustecer al movimiento revolucionario preparando la emergencia de la situación revolucionaria, el golpe de gracia al antiguo orden, siempre lo ha de dar la fuerza armada a disposición del movimiento revolucionario. Lo que no quiere decir que estas formas no armadas no sean importantes o significativas si están bien orientadas, ya que su papel de debilitar al adversario y de fortalecer al movimiento revolucionario crea el cuadro favorable que se configura cuando se ha llegado a generar una situación revolucionaria.

El comportamiento del imperialismo y sus agentes en América latina en la nueva situación que analizamos, junto con poner de manifiesto el carácter violento de su política, ha señalado también el marco continental en que se desenvuelve el proceso político latinoamericano, al concebir y realizar una estrategia polftico-militar de carácter continental para hacer frente a la subversión.

Ahora bien, la formulación de una estrategia continental contrarrevolucionaria significa que en el trasfondo del acontecer político de los últimos años, se ha ido constituyendo y perfilando por sobre los estados nacionales latinoamericanos, una especie de superestado continental, especialmente estructurado sobre la base de la vinculación formal e informal cada vez más estrecha de las fuerzas armadas de los países latinoamericanos bajo el liderazgo del Pentágono. Si se piensa que lo que define esencialmente al Estado es la monopolización 
legítima de la violencia en un territorio dado, lo que está ocurriend̦o en América latina es que en la medida que los pactos y acuerdos militares hemisféricos han ido configurando un dispositivo armado continental al servicio de la mantención del orden social vigente, en esa misma medida ha ido emergiendo un superestado continental, con un papel político conservador determinado, al lado del cual los diversos estados nacionales se desempeñan como agentes suyos, con autonomía administrativa, pero cuyo papel político conservador les está determinado por el carácter y la fuerza de los intereses sociales que se expresan políticamente en este superestado hemisférico.

La respuesta al superestado hemisférico y a su estrategia contrarrevolucionaria no puede ser otra que la continentalización del proceso revolucionario a través de la formulación de una estrategia común para hacerle frente en el plano político y especialmente en su nivel armado. Esta estrategia continental revolucionaria implica el que el enemigo que en último término habrá de enfrentarse es la fuerza armada hemisférica; vale decir en el terreno concreto, la fuerza armada de los Estados Unidos.

Asf planteadas las cosas, no cabe ya pensar en veinte procesos politicos revolucionarios separados e independientes en América latina, cada uno de los cuales puede tener un destino y un desenlace diferente. No. Se va diseñando y tomando forma cada vez más, un solo proceso revolucionario latinoamericano que va comprometiendo al, acontecer político de cada país, como un momento suyo, como un episodio que sólo tiene sentido en la medida que se inserta en el conjunto continental del proceso.

Cada movimiento revolucionario particular de un país es cada vez. más un destacamento de una fuerza política común y conjunta que surge trabajosa, pero nitidamente de la forma real que asume la lucha política en el continente y que se manifiesta en los planos ideológicos, orgánicos y militares. Por lo mismo, la consumación de la victoria revolucionaria no puede ya producirse en un plano nacional sino sólo en el plano continental. La toma del poder por las fuerzas revolucionarias en un país dado, es ahora sólo una etapa de una empresa que va mucho más allá de ese triunfo parcial, que sólo puede consumarse, incluso en ese supuesto pafs, como resultado de la victoria de la Revolución en escala continental. No habrá ya una segunda Cuba, en el sentido que no podrá consumarse la victoria revolucionaria en pais alguno de América latina sin la derrota imperialista continentalmente considerada.

Esto significa que cada destacamento nacional del movimiento revolucionario debe subordinar su propia estrategia y táctica al destino del conjunto del movimiento revolucionario continental, subordi- 
nando su propio punto de vista nacional, al punto de vista y al interés común. Las guerrillas en un país no son propias de ese país, sino propias del conjunto del movimiento. Y donde no haya en un momento condiciones para traducir la lucha en términos armados, es misión del movimiento revolucionario de ese país el ayudar la lucha armada de los otros destacamentos nacionales. Recíprocamente, el desarrollo de la lucha armada en un país crea condiciones que hacen posible que ésta estalle en otro, que aisladamente bien pudiera no estar en condiciones de promoverla.

El símil con la Guerra de la Independencia Americana es especialmente adecuado para visualizar el carácter continental que está ašumiendo el proceso revolucionario contemporáneo en América latina. La lucha contra el superestado español, enemigo común para las nacientes repúblicas hispanoamericanas, determinó el carácter continerıtal de la guerra, en la que se confundieron en un solo proceso bélico los esfuerzos de argentinos, chilenos, peruanos y grancolombianos. El desenlace final del conflicto; en Ayacucho, no fue una victoria peruana ni de alcance sólo peruano, sino fue un triunfo americano, de proyección americana.

Los rasgos armado y continental de la lucha de liberación de Jos pueblos latinoamericanos se condicionan reciprocamente. Asi, la oportunidad y forma en que se eleve al plano armado la lucha de los distintos destacamentos nacionales, dependerá tanto de sus condiciones internas como de las necesidades del conjunto del movimiento y del reflejo que este conjunto produzca en el seno de cada país.

\section{LAS DIVERSAS FORRMAS DE LUCHA ARMADA: LA GUERRILLA}

Las.formas que ha de asumir la lucha armada en cada país, en la medida que dependan de las condiciones internas, son un problema de hecho que al nivel actual del desarrollo del movimiento debe ser resuelto internamente por cada vanguardia revolucionaria.

No hay una sola forma de lucha armada. Existe la guerra de guerrillas, la guerra civil revolucionaria, la insurrección popular armada, como la de Octubre Rojo, la guerrilla urbana, etc.

Dadas las condiciones prevalecientes en la mayor parte de América latina, en sus más extensas y más pobladas áreas, es la guerrilla la forma fundamental de la lucha armada para el continente.

En efecto, en esas áreas geográficamente más extensas, demográficamente más pobladas y polfticamente más inestables, las condiciones son particularmente favorables para la guerrilla. La topografía del terreno, la cubierta selvática, la tensión social prevaleciente en los medios campesinos y la ausencia de una real participación polf́tica 
de esas masas en el proceso político del país, determinan que sea posible establecer una base guerrillera capaz de desarrollarse progresivamente, alli donde esas condiciones imperen².

La circunstancia de que en la mayor parte de América latina prevalecen condiciones naturales y sociales favorables para la forma guerrillera de la lucha armada, que hace de esa vía la fundamental dentro del continente, no quiere decir que en determinados contextos nacionales o regionales no puedan ser otras las formas armadas en que desemboque el proceso político. En Bolivia en 1952, por ejemplo, la Revolución armada asumió formas semejantes a las de la insurrección rusa de 1917 y no las de la lucha de guerrillas.

En otras palabras, si bien ningún país latinoamericano puede escapar al proceso político único que lo está comprometiendo y que tiene esencialmente un carácter armado y continental, puede que en algún o algunos países no sea la guerrilla la forma en que se manifieste el carácter armado de la lucha, o no sea la guerrilla allí la vía armada principal.

Allí donde sea la guerrilla la vía armada fundamental, es en la guerrilla y de la guerrilla donde va a generarse la fuerza política revolucionaria y donde va a germinar el nuevo poder revolucionario. Es la lucha guerrillera no sólo un frente de combate contra el adversario, sino también el crisol donde se forja el instrumento revolucionario, y el medio que permite la maduración de la conciencia política y la creación y emergencia del liderazgo revolucionario.

No tiene sentido, pues, el querer hacer de la guerrilla el "brazo armado" de un movimiento político dirigido desde la ciudad por una fuerza o partido que manipule a la guerrilla en función de una línea política de corte tradicional. Ello equivale a convertir a la guerrilla en una herramienta de presión para ayudar a una lucha política que se desenvuelve fundamentalmente por otros cauces. Del desacuerdo sobre esta cuestión derivan las graves discrepancias producidas entre la Revolución Cubana y el Pạrtido Comunista de Venezuela.

La guerrilla no debe ser, pues, un instrumento de presión al servicio de una política tradicional, sino el instrumento destinado a forjar al movimiento revolucionario, a constituir el embrión del poder revo. lucionario y a triunfar militarmente sobre la reacción.

El foco guerrillero, así entendido, da origen al foco político, lo antecede en cierta manera, en la medida que es la expansión y conso-

\footnotetext{
${ }^{2 " E n}$ muchos paises, las especiales condiciones del campo, una topografía favorable y una base social potencialmente revolucionaria, unidas a la especial adaptación de los medios téenicos y de los ejércitos profesionales para reprimir al pueblo en las ciudades, e incapaces en cambio de adaptarse a la guerra irregular, hacen de la guerrilla la fundamental expresión de la lucha armada, la escuela más formidable de revolucionarios y su vanguardia indiscutible". (De la Declaración General de la Primera Conferencia de olas).
} 
lidic ción de la base guerrillera el polo de atracción alrededor del cual har de aglutinarse las fuerzas sociales favorables a la revolución.

La guerrilla latinoamericana no es una guerra campesina, sino una guerra en el campo. Esto quiere decir que el foco no comienza como expresión madura y superior de un movimiento campesino favorable a la revolución, preexistente, sino al contrario, es el foco guerrillero el que hace madurar la conciencia campesina hasta convertir en un últino término a la guerrilla en el campo, en una guerra popular. El loco guerrillero sirve para crear conciencia política y no es el resultante del desarrollo de la misma en el escenario elegido, como es el ciso del Vietnam.

Lo contrario ocurre allí donde no es la guerrilla la forma armada funclamental. En estas otras condiciones, es el foco político el que prinıro se desarrolla y de su progresivo desenvolvimiento deriva en última instancia su expresión armada. En este caso, el proceso político, revolucionario antecedente a la lucha armada, y su radicalización y enfrentamiento con el adversario lo conduce a elevarse al plano armado, sea en la forma de guerra civil revolucionaria, de insurrección armada de masas, etc. ${ }^{3}$.

\section{EL ANTIMPERIALISMO, CONTENIDO FUNDAMENTAL DE LA DOCTRINA OLAS}

El contenido fundamental de la Revolución Latinoamericana es el antimperialismo. En las condiciones actuales, la línea divisoria entre los partidarios y los adversarios de la Revolución pasa por el meridiano del antimperialismo.

Esto no erá así antes de la Revolución Cubana. Existían entonces sectores sociales que sustentaban posiciones antimperialistas más o menos avanzadas y que sin embargo no eran revolucionarios. Ahora la situación ha cambiado, no se puede ser antimperialista consecuente sin convertirse en revolucionario, y no se puede ser revolucionario si no se es básicamente antimperialista.

La experiencia de la Revolución Cubana y su radicalización progresiva hasta culminar en el socialismo a través de la lucha antimperialista consecuente, demuestra que hoy, el enfrentar al imperialismo significa enfrentar a todo el orden social vigente, del cual el imperialismo es el gendarme armado, de manera que quien se proponga combatir al imperialismo no podrá limitar su acción a la mera recuperación, por ejemplo, de las riquezas naturales en su poder, sino

sEl tema alusivo al carácter de la gucrilla latinoamericana ha sido exhaustivamente desarrollado en los ensayos de Regis Debray, bastante conocidos por el público continental, razón por la cual hemos sintetizado al máximo los aspectos relativos a la guerrilla contenidos en la Doctrina de la ous. 
deberá necesariamente enfrentar a todos los intereses conservadores indisolublemente unidos políticamente con él. $\mathrm{Y}$ en esa misma medi$\mathrm{da}$, el progresivo desarrollo del proceso revolucionario conduce nectsariamente a su radicalización y su transformación en una Revolución Socialista. Dicho de otro modo, enfrentar ahora al imperialismo, quiere decir en último término, ubicarse junto a los estados socialistas, junto a todos los pueblos de Africa y Asia que combaten en contra suya, quiere decir colocar en tela de juicio las bases propietarias del sistema vigente y adoptar por último una posición socialista.

En el contexto sociopolitico actual del continente, es imposible aspirar, como lo pretenden los gobiernos reformistas y desarrollistas, a mantener una posición antimperialista limitada a ciertos aspectos económicos, con independencia de sus aspectos políticos. La lógica del proceso político tal como está planteada hoy en día, lleva a esos gobiernos, necesariamente, o a capitular por último frente al imperialisno, o a ser derrocados finalmente por las fuerzas sociales cuyos intereses amenazan, con su aprobación y hasta su aplauso. $Y$ ello ocurre porque estos gobiernos no pueden escapar a su condición de administradores por cuenta ajena del orden social vigente en sus países, de agentes de una política contrarrevolucionaria de alcance no sólo continental sino mundial. Al querer evadir ese papel que objetivamente tienen que desempeñar, sólo consiguen ser desplazados del poder por otras fuerzas que puedan desempeñar mejor el papel que necesariamente deben cumplir dentro del sistema político del superestado hemisférico.

Resulta ocioso así, querer precisar desde el comienzo el carácter de la Revolución Latinoamericana, definiéndola como democráticoburguesa, antifeudal y antimperialista o socialista. Las discusiones al respecto son hoy bizantinas. Quien quiere hacer la revolución en América latina encontrará al imperialismo oponiéndosele, y quien se opone al imperialismo necesariamente terminará por hacer la revolución.

La única condición del revolucionario es, pues, la de ser antimperialista consecuente. $\mathrm{Y}$ el movimiento revolucionario debe aspirar a unir a todas las fuerzas auténticamente antimperialistas, cualesquiera que sean su filiación ideológica o su ubicación social. Ahora no hay lugar ya para burgueslas antimperialistas, de manera que en el hecho desaparece el problema que durante tanto tiempo sirvió de tema para discusión en los circulos de izquierda, acerca de la convenien ia o no de marchar con la burguesía nacional progresista durante la etapa democrática de la revolución. Ahora la burguesía sabe que quien está contra el imperialismo está contra ella, y que quien está contra ella está contra el imperialismo. 
La unificación de todas las fuerzas antimperialistas dentro de cada país y dentro del continente, pasa a ser así la forma concreta de conseguir la unidad de los revolucionarios y a favorecer con ello el progresivo desarrollo de la Revolución.

\section{EL PROBLEMA DE LAS VANGUARDIAS}

El nuevo contexto sociopolítico del continente plantea al movimiento revolucionario nuevas tareas y nuevas formas de lucha. Los partidos de izquierda tradicionales, cualquiera que haya sido o sea su autodefinición ideológica o política, deben readaptarse a las nuevas condiciones y convertirse en el hecho en fuerzas revolucionarias. Si no son capaces de hacerlo, pierden su condición de vanguardia de la que hasta ahora habian presumido. No hay más vanguardias políticas en el continente que las que en la práctica demuestren su capacidad revolucionaria. "El deber de todo revolucionario es hacer la Revolución", reza la Segunda Declaración de La Habana. Queda invalidado pues, todo privilegio de antigüedad $u$ ortodoxia doctrinaria, para calificar el carácter de vanguardia revolúcionaria de cada movimiento político en el continente.

\section{¿QUÉ ES OLAS?}

Conforme esta perspectiva ideológica bosquejada en los párrafos precedentes ¿qué es la Onganización Latinoamericana de Solidaridad?

olAs podría definirse de acuerdo con las consideraciones que ante. ceden, como la forma orgánica y embrionaria en que se refleja la toma de conciencia del carácter armado y continental que está asumiendo la lucha revolucionaria en América latina. Si bien olAs es un reflejo de las nuevas características de la lucha revolucionaria, es también de rechazo, una agencia destinada a estimular y promover el desarrollo y la profundización de dicha lucha con tales caracteres.

Su carácter embrionario alude a la circunstancia de que su destino y futuro desarrollo y la amplitud del papel que cumpla, dependerá de la medida en que se continentálice el proceso revolucionario y se requiera por lo mismo de una estrategia común cada vez más precisa para llevarlo a término.

\section{OLAS Y LA QUTERELLA CHINO-SOVIÉTICA}

Aunque explícitamente no se cuestiona en las resoluciones de la Primera Conferencia de olas, la política de coexistencia pacifica sostenida por el movimiento comunista internacional que sigue la orientación del Partido Comunista de la Unión Soviética, ni se toma 
partido tampoco en la querella ideológica que dicha tendencia mantiene con el Partido Comunista Chino y sus seguidores, nos parece innegable que global y estratégicamente hablando, hay una marcada consistencia entre los puntos de vista ideológicos que informan la Doctrina oLAs, tal como nosotros la entendemos, con los planteamientos básicos de la posición china para apreciar el momento político mundial, en la medida que esa posición itende a centrar el proceso político mundial en un enfrentamiento ecuménico de carácter violento entre el imperialismo yanqui, convertido en gendarme armado de la reacción mundial y las fuerzas antimperialistas que pugnan por derrotarlo definitivamente, abriendo el paso para la Revolución Socialista en escala también mundial.

\section{OLAS Y LA TRADIGIÓN REVOLUGIONARIA DE AMÉRICA LATINA}

Es interesante destacar, por último, que insistentemente los documentos emanados de la Conferencia de olas recurren a la propia historia de América latina para buscar las fuentes del actual movimiento revolucionario y, en especial, para destacar el carácter armado y continental de su lucha. No es una casualidad que la Conferencia se haya inaugurado en una sesión presidida por la efigie de Bolívar y se haya cerrado en un acto ante un proscenio en cuyo trasfondo se destacaba la figura del Comandante Guevara.

\section{ANEXo}

Parte final de la Declaración General de la Primera Conferencia de la Organización Latinoamericana de Solidaridad (La Habana - agosto de 1967).

Nosotros, representantes de los pueblos de nuestra América, conscientes de las condiciones que existen en el continente, sabedores de la existencia de una estrategia común contrarevolucionaria que dirige el imperialismo yanqui,

\section{PROCLAMAMIOS:}

1. Que constituye un derecho y un deber de los pueblos de América lacina hacer la revolución.

2. Que la revolución en América latina tiene sus más profundas raí- ces históricas en el movimiento de liberación contra el colonialismo europeo del siglo diecinueve, $y$ contra el imperialismo en este siglo. La epopeya de los pueblos de América y las grandes batallas de clase contra el imperialismo que han librado nuestros pueblos en las décadas anteriores constituyen la fuente de inspiración histórica del movimiento revolucionario latinoamericano.

3. Que el contenido esencial de la revolución en América latina es. 
tá dado por su enfrentamiento al imperialismo y a las oligarquias de burgueses y terratenientes. Consiguientemente, el carácter de la revolución es el de la lucha por la independencia nacional, la emancipación de las oligarquías y el camino socialista para su pleno desarrollo económico y social.

4. Que los principios del marxismo- leninismo orientan al movimiento revolucionario de Amérića latina.

5. Que la lucha revolucionaria armada constituye la línea fundamental de la Revolución en América latina.

6. Que todas las demás formas de lucha deben servir y no retrasar el desarrollo de la linea fundamental que es la lucha armada.

7. Que para la mayoría de los paises del continente el problema de organizar, iniciar, desarrollar y culminar la lucha armada constituye hoy, la tarea inmediata y fundamental del movimiento revolucionario.

8. Que aquellos palses en que esta tarea no está planteada de modo inmediato de todas formas han de considerarla como una perspectiva inevitable en el desarrollo de la lucha revolucionaria en su pais.

9. Que a los pueblos de cada país y a sus vanguardias revolucionarias corresponderá la responsabilidad histórica de echar hacia adelante la revolución en cada uno de ellos.

10. Que la guerrilla -como embrión de los ejércitos de liberaciónconstituye el método más eficaz. para iniciar y desarrollar la lucha revolucionaria en la mayoría de nuestros países.

11. Que la dirección de la reviolución exige como un principio organizativo la existencia del mando unificado político y militar como garantía para su éxito.

12. Que la solidaridad más efectiva que pueden prestarse los movimientos revolucionarios, entre sí, la constituye el desarrollo y culminación de la propia lucha en el seno de cada país.

13. Que la solidaridad con Cuba y la colaboración y cooperación con el movimiento revolucionario en armas constituyen un deber insoslayable de tipo internacional de todas las organizaciones antiimperialistas del continente.

14. Que la Revolución Cubana, como símbolo del triunfo del movimiento revolucionario armado, constituye la vanguardia del movimiento antimperialista latinoamericano. Los pueblos que desarrollan la lucha armada, en la medida en que avanzan por ese camino se sitúan también en Ja vanguardia.

15. Que los pueblos directamente colonizados por las metrópolis europeas o sujetos por dominación colonial directa a los Estados 
Unidos en su camino para la liberación tienen como objetivo inmediato $y$ fundamental, el luchar por la independencia $y$ mantenerse vinculados a là lucha general del continente como única forma de evitar ser absorbidos por el neocolonialismo norteamericano.

16. Que la Segunda Declaración de La Habana, recogiendo la, hermosa tradición revolucionaria de los últimos 150 años de la historia de América, constituye un documento programático de la Revolución Latinoamericana que los pueblos de este continente durante los últimos cinco años han confirmado, profundizado, enriquecido y radicalizado.

17. Que los pueblos de América latina no tienen antagonismos con ningún otro pueblo del mundo y le extienden su mano fraternal al propio pueblo de los Estados Unidos, al que exhorta a luchar contra la polf́tica represiva de los monopolios imperialistas.

18. Que la lucha en América latina fortalece sus vinculos de solidaridad con los pueblos de Asia y Africa y de los países socialistas, y con los trabajadores de los países capitalistas, especialmente con la población negra de los Estados Unidos que sufre a la vez la explotación de clase, la miseria, el desempleo, la discriminación ra- cial y la negación de los más elementales derechos humanos $y$ constituye una importante fuerza a considerar en el contexto de la lucha revolucionaria.

19. Que la lucha heroica del pueblo de Vietnam presta a todos los pueblos revolucionarios que combațen al imperialismo, una inestimable ayuda y constituye un ejemplo inspirador para los pueblos de América latina.

20. Que hemos aprobado los Estatutos y creado el Comité Permanente con sede en La Habana, de la Organización Latinoamericana de Solidaridad, la que constituye la genuina representación de los pueblos de América latina.

Nosotros, revolucionarios de nuestra América, la América al Sur del Río Bravo, sucesores de los hombres que nos dieron la primera independencia, armados de una voluntad inquebrantable de luchar y de una orientación revolucionaria y científica y sin otra cosa que perder que las cadenas que nos oprimen,

\section{AFIRMAMOS:}

Que nuestra lucha constituye un aporte decisivo a la lucha histórica de lā humanidad por librarse de la esclavitud y de la explotación.

EL DEBER DE TODO REVOLUCIONARIO ES hacer la revolucion. 